\title{
Current views concerning the influences of murine hepatic endothelial adhesive and cytotoxic properties on interactions between metastatic tumor cells and the liver Hui Helen Wang*1, Hongming Qiu ${ }^{2}, \mathrm{Ke} \mathrm{Qi}^{3}$ and F William Orr ${ }^{4}$
}

\begin{abstract}
Address: ${ }^{1}$ Department of Health Sciences, Red River College and Department of Pathology, Faculty of Medicine, University of Manitoba, Winnipeg, Manitoba, Canada, ${ }^{2}$ Department of Pathology, Health Sciences Center, University of Manitoba, Winnipeg, Manitoba, Canada, ${ }^{3}$ Department of General Surgery, Nanshan Hospital, Shenzhen, Guangdong, China and ${ }^{4}$ Department of Pathology, Faculty of Medicine, University of Manitoba, Winnipeg, Manitoba, Canada

Email: Hui Helen Wang* - wangh0@cc.umanitoba.ca; Hongming Qiu - qiuxx005@yahoo.com; Ke Qi - qike1792002@yahoo.ca; F William Orr - worr@cc.umanitoba.ca

* Corresponding author
\end{abstract}

Published: 09 December 2005

Comparative Hepatology 2005, 4:8 doi:10.1 186/1476-5926-4-8
Received: 2I September 2005

Accepted: 09 December 2005

This article is available from: http://www.comparative-hepatology.com/content/4/1/8

(c) 2005 Wang et al; licensee BioMed Central Ltd.

This is an Open Access article distributed under the terms of the Creative Commons Attribution License (http://creativecommons.org/licenses/by/2.0), which permits unrestricted use, distribution, and reproduction in any medium, provided the original work is properly cited.

\begin{abstract}
Substantial recent experimental evidence has demonstrated the existence of reciprocal interactions between the microvascular bed of a specific organ and intravascular metastatic tumor cells through expression of adhesion molecules and nitric oxide release, resulting in a significant impact upon metastatic outcomes.

This review summarizes the current findings of adhesive and cytotoxic endothelial-tumor cell interactions in the liver, the inducibility, zonal distribution and sinusoidal structural influences on the hepatic endothelial regulatory functions, and the effects of these functions on the formation of liver cancer metastases. New insights into the traditional cancer metastatic cascade are also discussed.
\end{abstract}

\section{Introduction}

The formation of a metastatic tumor in the secondary organ is the result of dissemination of a primary cancer cell, survival in the circulation, passing through the vascular bed in the distant organ and cancer cell proliferation [1-4]. Cancer metastasis is known to be an inefficient process, which reflects the fact that most of the intravascular cancer cells are killed within blood vessels or lymphatic channels $[5,6]$. Metastasis is accomplished in a step-wise or metachronous fashion [6,7]. More recent studies using mouse and rat models and in vivo video microscopy have demonstrated that the initial steps of the haematogenous metastatic process, from cancer cells entering the bloodstream to extravasating into secondary organs, are completed with remarkable efficiency $[8,9]$. The inefficiency is more associated with the subsequent steps involving cell division and formation of micrometastases by extravasated cancer cells in the secondary site $[7,8,10]$. In contrast, other studies have indicated that the majority of disseminating tumor cells die rapidly in the blood circulation and can not pass the first capillary bed they encounter $[8,11-13]$. With the metastatic cascade being well-outlined in the literature, the specific underlying mechanisms of tumor cell loss in the circulation and secondary organs, and the determinant factors for metastases formation still remain to be fully elucidated $[3,10,14]$. 
Recent in vivo and in vitro experimental evidence from various laboratories strongly suggests that, during the interactions between an organ microvascular bed and intravascular tumor cells, nitric oxide (NO) plays a significant role as a cytotoxic natural defensive effector, produced by the vascular endothelial cells, to exert toxic effects on invading tumor cells, interact with endothelial adhesion molecules and regulate the subsequent metastatic tumor formation in the secondary organ $[10,15,16]$. This review surveys this new evidence and reviews current opinions derived mostly from animal studies on how endothelial and tumor cells interact with each other through adhesive and cytotoxic properties in the hepatic microvascular bed. We describe how these interactions and metastases formation can be influenced by sinusoidal structural and functional characteristics and alterations. The identification of this host internal defensive mechanism gives new insights into cancer metastatic inefficiency, and identifies a new barrier in the classic model of the cancer metastatic cascade.

\section{Influence of hepatic adhesive properties Endothelial-tumor cell interactions are regulated by inducible adhesion molecules expressed in the liver}

Since the "seed and soil" theory proposed by Stephen Paget, there has been a long history of research into the reasons for organ-specific cancer metastasis $[17,18]$. The liver is a common site for metastasis of human cancer and a convenient target for experimental studies of metastasis. From the latter it is apparent that endothelial cell surface adhesion molecules have an extensive role in regulating cancer cell site-specific arrest, transendothelial migration and metastases formation [3,19-23].

Expression of various hepatic endothelial adhesion molecules has been demonstrated to be selectively inducible by cytokines, bacterial lipopolysaccharide (LPS) or arresting tumor cells in the liver microvascular bed. In turn, these adhesion molecules can be shown to regulate the arrest of circulating cancer cells in the hepatic sinusoids. For example, interleukin- $1 \alpha$ (IL- $1 \alpha)$ pretreatment of mice altered the melanoma cell (B16F1) arrest pattern from $32 \mu \mathrm{m}$ beyond the sinusoidal inlet to larger terminal portal venules (TPV) observed by intravital videomicroscopy, suggesting increased adhesive interactions between endothelial and tumor cells following IL- $1 \alpha$ stimulation [24]. Interleukin-18 (IL-18) has been demonstrated in vivo and in vitro to promote liver metastasis by enhancing melanoma cell adhesion to the hepatic sinusoidal endothelial cells via microvascular VCAM-1 (vascular cell adhesion molecule-1) expression [25-27]. With a basal expression level of ICAM-1 (intercellular adhesion molecule-1), minimal expression of VCAM-1 and no expression of E-selectin or $\alpha \mathrm{v}$ integrin in unstimulated mouse livers, $1 \mu \mathrm{g} / \mathrm{g}$ body weight of LPS i.p. selectively induced the expression of ICAM-1 (4-48 h), VCAM-1 (4-24 h) and E-selectin $(2 \mathrm{~h})$ on the sinusoidal lining cell surface, while $\alpha v$ integrin expression was unchanged [28,29]. LPS did not significantly alter the expression of VLA-4 (very late antigen-4, counter receptor of VCAM-1) or LFA-1 (leukocyte functional antigen-1, counter receptor of ICAM-1) on melanoma cells either in vivo or in vitro [30]. Tumor necrosis factor (TNF) induced sustained VCAM-1 expression within $4 \mathrm{~h}$ in the lung, liver and kidney of mice [31], and increased the adhesion of highly metastatic murine carcinoma cell line H-59, and human colorectal carcinoma lines HM 7 and CX-1 to murine hepatic endothelial cells in the primary culture. This effect was completely abolished by a monoclonal antibody to murine E-selectin [21]. Mannose receptor-mediated endothelial cell activation also contributed to B16 melanoma cell adhesion and metastasis in the mouse liver [32].

The expression of sinusoidal adhesion molecules is affected by metastatic cells in the hepatic microenvironment. The arrest of B16F1 melanoma cells in the liver sinusoids (following mesenteric vein injection) induced focal expression of VCAM-1 and more diffuse expression of ICAM-1 around the melanoma cell arrest sites [30]. Similarly, the arrest of murine carcinoma line H-59 cells after intrasplenic injection induced E-selectin expression on the hepatic sinusoidal endothelium between 2-24 h [33]. The expression of ICAM-1, VCAM-1, E-selectin and $\alpha v$ integrin was all induced to different degrees by the growth of melanoma tumors in the peritoneal cavity without liver metastasis in the mouse [28]. In a study on progression of mouse melanoma (B16-BL6) spontaneous metastasis, organ specific induction of VCAM-1 was observed in the cardiac, hepatic and cerebral vascular beds 4 weeks following the resection of primary tumors when metastatic pulmonary burden was maximal [34]. Intrasplenically injected B16 melanoma (B16M) cells also increased the expression of VCAM-1 significantly on hepatic sinusoidal endothelial cells within the first $24 \mathrm{~h}$, which correlated with the increased in vitro adhesion of B16M cells to hepatic sinusoidal endothelial cells isolated from B16M cell-injected mice [35].

The mechanisms and significance of the selectivity of adhesion molecule induction have not been fully described at this stage. However, the inducibility of various adhesion molecules on the hepatic endothelial cell surface by different microenvironmental stimuli has provided a potential diversity and flexibility for sinusoidal endothelial cells to participate in tumor defensive responses when intravascular metastatic cancer cells are present. 


\section{Impact of sinusoidal structural and functional characteristics on adhesion molecule induction}

The micro-structural and functional heterogeneity in the liver across its functional unit of acinar zonation has been well-described in the literature [36-39]. This hepatic zonal heterogeneity has also played a significant role influencing the patterns of induced adhesion molecule expression. Differential zonal expressions of certain adhesion molecules induced by LPS stimulation have been demonstrated [28]. With a weak expression around the terminal portal venule regions (acinar zone 1) under basal conditions, ICAM-1 was induced to a uniform strong expression (4-48 h) across each entire acinus in the liver following LPS administration. On the contrary, VCAM-1 and Eselectin both had minimal or no expression in unstimulated livers, but had significantly stronger expression in acinar zone 1 than zone 2 and 3 after LPS stimulation, with VCAM-1 expressed between 4-48 h and E-selectin 2$12 \mathrm{~h}$ [28]. LPS stimulation also increased the retention of B16F1 melanoma cells in the liver between 8-24 h, especially in the terminal portal venule region presumably through increased expression of adhesion molecules, ICAM-1 and VCAM-1 [30]. IL-1 zonal heterogeneity of mannose receptor-mediated ligand endocytosis in the mouse and rat liver was also observed using flow cytometry following LPS stimulation [40,41]. In human studies, major differences have been noted in the composition of the portal tract and sinusoid with regard to endothelial and parenchymal cell expression of cell-cell and cellmatrix adhesion molecules during inflammatory reactions in human liver grafts [42]. Differential expression of various adhesion molecules has been reported between normal and inflamed livers, or livers rejected after transplantation in humans. The selectins ELAM-1 (endothelial leukocyte adhesion molecule) and CD62 (cluster of differentiation 62) were basally expressed and inducible on portal tract endothelia and central vein endothelia with acute and chronic human liver inflammation, although sinusoidal endothelia lack this mechanism even with severe inflammation [43]. Portal and sinusoidal endothelia showed a different expression and inducibility of VCAM-1, ICAM-1, ICAM-2, and LFA-3 (leukocyte functional antigen-3) in human livers [43].

In addition to the impact of hepatic zonal heterogeneity on adhesion molecule expression, alterations in the liver sinusoidal architecture also significantly change the endothelial cell surface molecule expression and tumor cell behavior patterns. Using a murine liver cirrhosis model, where the sinusoidal lumens were narrowed due to the formation of fibrous tissue, the expression of adhesion molecules ICAM-1 and VCAM-1 was found to be significantly increased (stronger in acinar zone 1) on the endothelial surface with E-selectin undetectable [44]. After injecting melanoma cells into the portal vein, melanoma cell retention in the cirrhotic liver terminal portal venule regions was also significantly increased in comparison with the control livers [44].

\section{Influence of hepatic cytotoxic properties}

Recent experimental evidence suggests that in addition to adhesion molecules, the hepatic sinusoid has other heterogeneous structural and functional properties that create a unique anatomical vascular bed in which endothelial lining cells exert antitumor effects with extensive diversity and flexibility to fight against invading metastatic tumor cells.

\section{Endothelial-tumor cell interactions induce nitric oxide release from the hepatic endothelium}

Direct and indirect evidence from the literature has supported the hypothesis that the hepatic sinusoidal microvasculature is toxic to metastatic tumor cells. Various experimental data obtained to date have indicated that the hepatic endothelium exerts its antitumor defensive effects through the release of NO and other reactive oxygen species (ROS) $[4,10,15,16,45-47]$. As with adhesion molecule expression, the cytotoxic regulatory functions in the liver have also been demonstrated to be inducible by microenvironmental stimuli.

The original evidence that hepatic endothelium-derived $\mathrm{NO}$ is induced by intravascular metastatic tumor cells was obtained by applying electron paramagnetic resonance (EPR) NO-spin trapping technologies into a classic murine melanoma metastatic model $[15,48,49]$. By injecting fluorescent microsphere-labeled B16F1 melanoma cells into the portal circulation of $\mathrm{C} 57 \mathrm{BL} / 6$ mice, a swift burst of $\mathrm{NO}$ was detected in liver samples within $5 \mathrm{~min}$ utes of cell injection. NO induced apoptosis in 20-30\% of the melanoma cells arresting in the liver after $4 \mathrm{~h} \mathrm{[15].}$ NO was identified and its cytotoxicity to melanoma cells was supported by finding that the nonselective NO synthase inhibitor L-NAME $\left(\mathrm{N}_{\mathrm{G}}\right.$-nitro-L-arginine methyl ester) blocked NO production and melanoma cell apoptosis in the sinusoids. The ability of a short burst of NO to cause apoptosis was further confirmed by detecting the apoptotic DNA fragmentation and cell membrane damage in B16F1 cells exposed to a NO donor for $5 \mathrm{~min}$ in vitro [15]. The mechanisms of tumor cell specific induction of NO release at the site of cell arrest have not yet been identified but are suggested to be partly due to tumor cell-induced vascular wall shear stress with circumferential stretch and isometric contraction (Lower levels of NO are released following injection of inert microspheres with similar diameters to melanoma cells) [15,50,51]. Using an in situ liver perfusion system, the cellular origin of the NO release following B16F1 cell arrest in the liver has been identified as periportal endothelial and sinusoidal lining cells, and hepatocytes adjacent to the arresting 

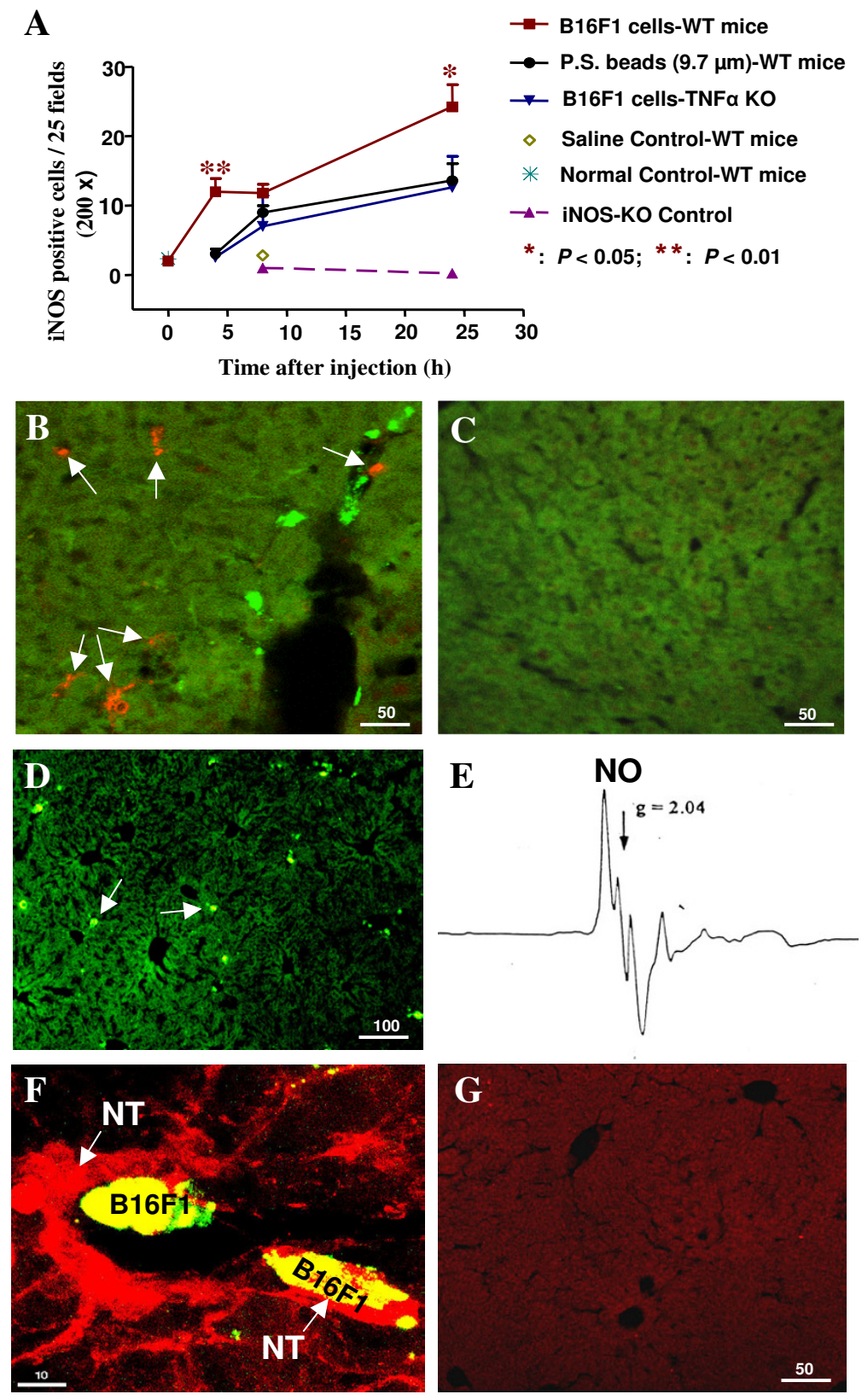

Figure I

B I 6F I melanoma cell-induced iNOS expression, NO production and nitrotyrosine formation in the mouse liver. (A): Induction of hepatic iNOS expression $(0-24 \mathrm{~h})$ in various strains of C57BL/6 mice injected with BI6FI melanoma cells or polystyrene (P.S.) beads. iNOS was detected by immunofluorescent double-labeling using rabbit anti-mouse iNOS as the primary and Cy ${ }^{\mathrm{TM}} 3$-conjugated goat anti-rabbit IgG as secondary antibodies. Data represent the mean \pm SE of iNOS positive cells in 25 fields of each mouse liver in the group $(n=5$ mice/group, at $200 \times$ magnifications). WT: Wild-type. KO: Knockout; (B): iNOS expression (orange, arrows) in sinusoidal lining cells and hepatocytes of a wild-type mouse liver at $24 \mathrm{~h}$ after injection of melanoma cells (green); (C): iNOS detection negative control in a normal wild-type liver without cell injection. (D): Liver sample excised immediately after BI6FI cell injection (arrows, $0 \mathrm{~h}, 100 \times$ ); (E): NO signal detected in the $0 \mathrm{~h}$ liver sample using EPR spectroscopy; (F): Nitrotyrosine (NT, red, arrows) detection in the same $0 \mathrm{~h}$ liver, by double-labeling immunohistochemistry using mouse anti-nitrotyrosine primary antibody, along the sinusoidal wall adjacent and inside the arresting tumor cells. (G): A negative control of NT detection in a wild-type mouse liver without tumor cell injection. Scale bars displayed in $\mu \mathrm{m}$. 
B16F1 cells [52]. The endothelial and sinusoidal lining cells released NO in an eNOS (endothelial NO synthase)dependent manner over a time of $500 \mathrm{sec}$, and hepatocytes over a longer period of time measured by fluorescent 4,5-diaminofluorescein diacetate (DAF-2 DA) used as the NO detection probe [52]. In addition to the immediate burst of endothelial eNOS-dependent NO production upon melanoma cell arrest in the liver, a delayed iNOS (inducible NO synthase)-dependent cytotoxic NO induction after $4 \mathrm{~h}$ of cell injection into the mesenteric vein has also been demonstrated, which was partially due to the shear forces generated by melanoma cell arrest in the sinusoids, and produced from both sinusoidal lining cells and hepatocytes detected by double-labeling immunohistochemistry [15] (Figure 1: A - C).

This evidence has been supported by findings from Umansky et al. [4,16] and Rocha et al. [53]. Using a wellcharacterized ESbL-lacZ mouse T lymphoma model, the authors have shown that a significant increase in NO production detected in vitro from ex vivo isolated liver endothelial cells and Kupffer cells coincided with the plateau phase (tumor retardation phase) of primary tumor growth and a low level of liver metastasis. They have also demonstrated that the activated host liver endothelial cells play dual roles in metastatic processes by expressing adhesion molecules and producing NO from iNOS activation $[4,16,53]$.

Edmiston et al. have shown that unstimulated murine sinusoidal endothelial cells produced ROS that were selectively toxic to weakly metastatic human colorectal carcinoma clone A cells, with the toxicity blockable by pretreatment with NO synthase inhibitor, superoxide dismutase or dexamethasone [54]. Coculture of ischemic liver fragments with human colorectal carcinoma cells killed more weakly metastatic clone A cells at $24 \mathrm{~h}$ than highly metastatic CX-1 cells because of the higher sensitivity to NO and ROS in clone A cells $[47,55]$. NO also induced apoptosis in different human neoplastic lymphoid cells and breast cancer cell lines through caspase activation pathways $[46,56]$.

\section{Endothelial-tumor cell interactions induce release of other inducible reactive oxygen species (ROS) from the hepatic endothelium}

In addition to NO, other cytotoxic ROSs are released from the liver endothelium and also possess antitumor cytotoxicity. In vitro, sinusoidal endothelial cells release hydrogen peroxide $\left(\mathrm{H}_{2} \mathrm{O}_{2}\right)$ which enhanced VLA-4 mediated melanoma cell adherence to the hepatic sinusoidal endothelium and caused tumor cytotoxicity after IL-1 treatment in mice $[57,58]$. Superoxide anion $\left(\mathrm{O}_{2}^{-}\right)$may be involved in the cytotoxicity of murine hepatic sinusoidal endothelial cells to weakly metastatic human colorectal carcinoma cells $[47,54,55]$. The important interplays between $\mathrm{NO}$ and other ROSs, such as $\mathrm{O}_{2}^{-}$, in cancer development and progression have been reviewed [45]. The rapid death of most cancer cells after delivery to some target organs has also been demonstrated to be a consequence of their mechanical interactions within the microvasculature [12].

The accumulated evidence to date has directed us to recognize the existence of a host natural defensive mechanism network in the hepatic microvasculature through the production of $\mathrm{NO}$ and other ROSs from the sinusoidal endothelium to generate cytotoxicity to invading intravascular tumor cells to fight against cancer metastasis in the liver.

\section{Impact of sinusoidal structural and functional characteristics on nitric oxide induction}

Similar to the inducible adhesion molecule expression under the influence of hepatic zonal heterogeneity, evidence suggests that the release of NO from the hepatic endothelium is restricted to specific anatomical zones. Using an in situ C57BL/6 mouse liver perfusion system, the levels of NO production without and with tumor cells in the liver were found to be much greater in acinar zone 1 than zone 2 and 3 by direct visualization of NO synthesis through deesterification and conversion of intracellular DAF-2 DA to DAF-2T [52]. In cirrhotic mouse livers with altered sinusoidal architecture, significantly lower levels of NO production were detected both under basal conditions (without tumor cells) and after tumor cell arrest by the same experimental system [44].

\section{Evidence of cytotoxic properties in extrahepatic microvascular beds}

The detection of a host defensive mechanism existing in the hepatic endothelium has raised the question of whether similar defense mechanisms also exist in other metastatic target organs. Direct in vitro lysis of metastatic tumor cells by cytokine-activated murine lung vascular endothelial cells has been demonstrated. NO (detected by nitrite concentration in the culture medium) produced by interferon gamma and TNF-activated lung vascular endothelial cells played a major role in the lytic destruction of reticulum cell sarcoma $[59,60]$. Rapid death of transformed metastatic rat embryo cells, occurred via apoptosis in the lungs $24-48 \mathrm{~h}$ after injection into the circulation of immune-deficient $\mathrm{nu} / \mathrm{nu}$ mice, has been reported [14,61].

Using EPR NO-spin trapping technologies, a significantly increased production of NO was detected in lung tissue samples between $20 \mathrm{~min}$ and $4 \mathrm{~h}$ after the tail vein injection of fluorescent microsphere-labeled B16F1 melanoma cells [49]. The EPR results were also supported in an iso- 
lated, ventilated and blood-free mouse lung perfusion model, where NO production in situ was observed in real time using intact organ microscopy techniques. Fluorescent NO signals (DAF-2T) increased rapidly at the site of tumor cell arrest in the lungs and continued to increase throughout 20 min thereafter $[49,62]$. NO contributed to tumor cell apoptosis since 3-fold more B16F1 cells subsequently underwent apoptosis in the lungs of wild-type mice compared to animals in which NO production was inhibited, in particular, in eNOS-deficient mice and NOS inhibitor L-NAME-pretreated mice [49].

The identification of a similar antitumor defensive mechanism in the pulmonary microvascular bed has reinforced the concept that the host can release NO and other ROSs as cytotoxic effector molecules to fight against the invading metastatic tumor cells in the microvascular beds of the first-line cancer metastatic organs, such as the liver and lung.

\section{Molecular mechanisms of nitric oxide-induced melanoma cell cytotoxicity}

The majority of reports indicate that the underlying molecular mechanisms for NO-induced tumor cell cytotoxicity are direct damage to DNA and the cell membrane, or activation of apoptosis-initiating caspases (cysteine proteases) causing tumor cell apoptosis and necrosis $[10,14,15,45-47,49,54,56,59,60]$. In addition, preliminary evidence also suggests that NO may induce oxidative damage on proteins through NO-superoxide-peroxynitrite and NO-nitrogen dioxide-nitrite pathways to form nitrotyrosine. The latter is the footprint of potent shortlived reactive nitrogen species, peroxynitrite (ONOO-) production in vivo, mediating NO-induced oxidative attacks on biological macromolecules [63-65] (Figure 1: D-G). More observations need to be made to provide supportive evidence along this direction.

\section{Interactions between nitric oxide and adhesion molecules in the hepatic microvascular bed}

The importance of interplays between NO and adhesion molecules in the regulation of liver cancer metastasis has been recognized and addressed in recent years $[10,19,20,45]$. The inducible murine hepatic microvascular adhesive and cytotoxic regulatory functions have been regulated by using LPS $[28,30]$. With enhanced local expression of VCAM-1 and ICAM-1 around B16F1 cell arrest sites in the liver, LPS significantly increased the retention of melanoma cells in the liver, especially in the terminal portal venule regions between 8 and $24 \mathrm{~h}$ after intramesenteric injection of melanoma cells [30]. LPS also significantly increased the levels of iNOS expression and tumor cell induced-NO production at $8 \mathrm{~h}$ after administration and cell injection, and increased the rates of B16F1 cell apoptosis in the terminal portal venule region [30].
These data have been interpreted to indicate that LPS stimulated a synergistic interaction by inducing both the hepatic endothelial adhesion molecule expression and NO release in the terminal portal venular regions, resulting in higher levels of tumor cell killing in this region in the liver [30]. The dual roles of activated host liver endothelial cells in murine lymphoma metastatic process have also been reviewed [16]. On one hand, upregulation of the expression of particular adhesion molecules is considered to lead to the increased tumor cell binding and stimulation of angiogenesis, and on the other hand, endothelial cells can contribute to host anti-metastatic responses by producing the cytotoxic molecule NO from arginine with the help of iNOS [16]. Synergistic interactions between LFA-1/ICAM-1 and lymphoma progression phases with cytotoxic NO production have been described [4]. Interactions between cytokine IL-18, VCAM- $1, \mathrm{H}_{2} \mathrm{O}_{2}$ and hepatic sinusoidal endothelial cells have also been demonstrated [35]. Recombinant catalase administered in vivo completely blocked the increase of VCAM-1 expression induced by $\mathrm{B} 16 \mathrm{M}$ cell arrest in the liver, and blocked in vitro $\mathrm{B} 16 \mathrm{M}$ cell adhesion to sinusoidal lining cells isolated from B16M cell-injected mice [35]. Incubation of hepatic endothelial cells with nontoxic concentrations of $\mathrm{H}_{2} \mathrm{O}_{2}$ directly enhanced VCAM-1-dependent B16M cell adhesion in vitro without proinflammatory cytokine mediation [35].

In addition to synergistic interactions between $\mathrm{NO}$ and adhesion molecules, their counteractive interactions have also been identified. NO reduces tumor cell adhesion to isolated rat postcapillary venules in vitro [66]. Anti-adhesive roles of constitutively produced NO in inhibiting leukocyte rolling and adhesion in the microcirculation have been described $[67,68]$. Oxidative stress in the liver can be caused by ischemia/reperfusion $(\mathrm{I} / \mathrm{R})$ injury when tumor cells entering the hepatic microcirculation obstruct hepatic sinusoids and temporarily occlude blood flow before the hepatic circulation is reestablished by either tumor cell death or invasion into the parenchyma $[8,55]$. The counteractive roles of $\mathrm{NO}$ with adhesion molecules, such as decreasing P-selectin and ICAM-1 mRNA expression, attenuating neutrophil accumulation and liver damage in hepatic ischemia/reperfusion injury have been reviewed [69-71]. IL-10 has also been shown to inhibit hepatic I/R injury by inhibiting the upregulation of iNOS expression following I/R injury [55]. The multifaceted roles and effects of NO and adhesion molecule interactions support the scenario that the host uses this flexible natural defensive mechanism to protect itself from a variety of disastrous oxidative injuries and tissue damages to the hepatic microvasculature. 
a Primary tumor

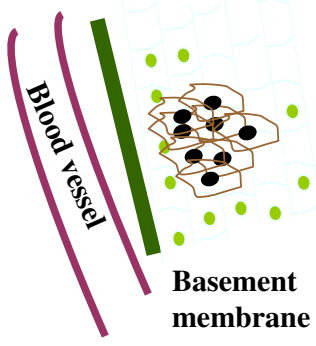

i Micrometastasis

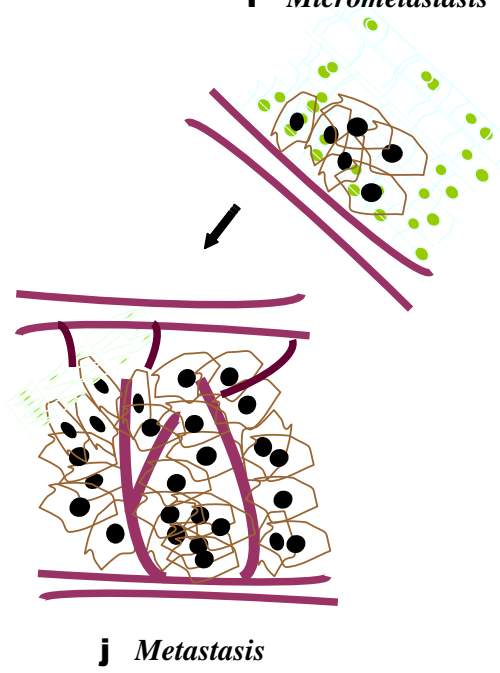

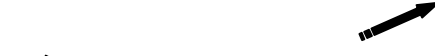

b Invasion

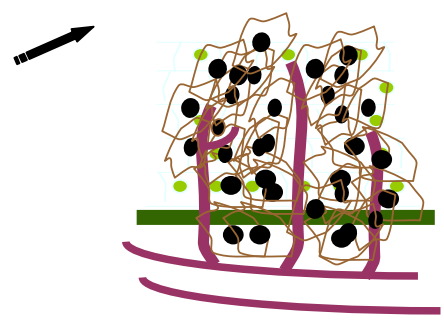

C Angiogenesis

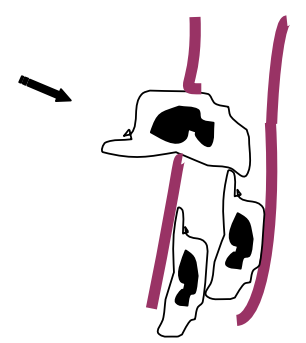

g Extravasation

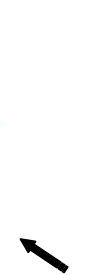

h

Migration

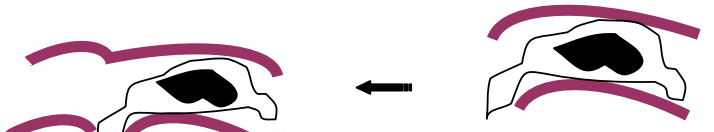

e Adhesion to blood vessel wall in distant organ
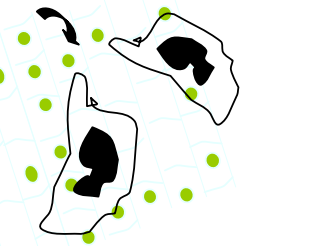

f Passing endothelial defense:

Tumor cell apoptosis and clearance by endothelium -derived NO

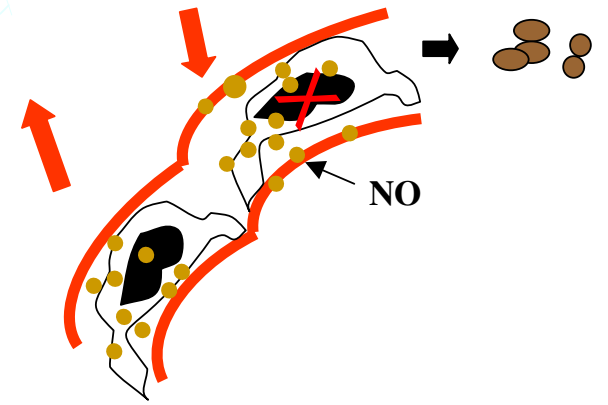

Figure 2

Modified classic metastatic cascade. Traditional metastatic cascade: Steps $\mathrm{a} \rightarrow \mathrm{b} \rightarrow \mathrm{c} \rightarrow \mathrm{d} \rightarrow \mathrm{e}, \rightarrow \mathrm{g} \rightarrow \mathrm{h} \rightarrow \mathrm{i} \rightarrow \mathrm{j}$. Modified metastatic cascade: Steps $\mathrm{a} \rightarrow \mathrm{b} \rightarrow \mathrm{c} \rightarrow \mathrm{d} \rightarrow \mathrm{e} \rightarrow \mathbf{f} \rightarrow \mathrm{g} \rightarrow \mathrm{h} \rightarrow \mathrm{i} \rightarrow \mathrm{j}$, with a new "f' step of passing through endothelial defense mechanisms included.

\section{Effects of sinusoidal adhesive and cytotoxic functions on metastasis}

Substantial experimental evidence supports the hypothesis that hepatic adhesive functions can regulate cancer metastatic outcomes in the liver. IL- $1 \alpha$ pretreated mice had 11-22-fold greater hepatic melanoma tumor burden than control mice pretreated with saline presumably through altering adhesive interactions between B16F1 cells and the hepatic microvasculature [24,72]. Liver sections from IL-1 $\alpha$-pretreated mice attracted 3 -fold more melanoma cells to adhere in vitro than control liver sections. Adhesion was blocked by antibodies to E-selectin, ICAM-1, VCAM-1 and $\alpha v$ integrin subunit [24]. A single dose of IL-1 receptor antagonist $(0.2 \mathrm{mg} / \mathrm{kg}$, i.p.) given 2 $\mathrm{h}$ before intrasplenic injection of melanoma cells reduced the number of hepatic metastases by $50 \%$ and metastatic volume by $70 \%$ compared with the vehicle-injected control mice [73]. Systemic inflammation induced by intravenous injection of IL-1 or LPS increased hepatic melanoma metastasis significantly in an IL-1 dependent manner [74]. E-selectin expression blockage by monoclonal antibody significantly reduced experimental liver metastasis in the mouse [21]. Blockade of VCAM-1 expression in vivo with specific antibodies, administered before B16M cell injection into the portal circulation, decreased sinusoidal retention of luciferase-transfected B16M cells by $85 \%$, and metastasis development by $75 \%$, indicating that VCAM-1 expression on tumor-activated sinusoidal endothelial cells had a prometastatic contribution [35].

In addition to such adhesive functions, hepatic cytotoxic properties alone or through interactions with adhesive 
function and hepatic vascular zonal heterogeneity have been demonstrated to contribute significantly to the inhibition of tumor growth in the secondary sites. With $2 / 3$ of intramesenteric injected-B16F1 cells arresting in the liver sinusoids, the rapid burst of $\mathrm{NO}$ induction triggered apoptosis in $1 / 4$ of the intravascular melanoma cells and significantly decreased the metastatic tumor burden in the liver [15]. Increased NO production by ex vivo isolated liver sinusoidal endothelial cells was detected in the tumor growth retardation phase in a well-characterized murine T lymphoma model, and the breakdown of this NO synthesis coincided with the second tumor expansion phase $[4,16,53]$. LPS has been demonstrated to inhibit melanoma metastases formation in the liver by inducing NO release and adhesion molecule expression in the hepatic endothelium, which was primarily located within the terminal portal venular region (acinar zone 1) [30]. Selective implantation and growth in rats and mice of experimental liver metastasis in acinar zone 1 has been demonstrated using B16 melanoma and Lewis lung carcinoma cell lines [75]. Cirrhotic livers with narrowed sinusoidal lumens were found to have decreased velocity of melanoma cell traveling in the sinusoids, decreased NO release and tumor cell apoptosis, and increased tumor cell proliferation and metastases formation in the liver [44]. The vascular-targeting agent ZD6126 was able to reduce the liver metastatic burden significantly in mice with extensive tumor necrosis, increased tumor cell apoptosis and a reduction in tumor-associated vasculature with disrupted and non-functional vascular channels within metastases with no blood flow [76]. In the pulmonary vascular bed, NO production following tail vein injection of B16F1 melanoma cells induced 3-fold higher apoptosis rate, $30 \%$ higher tumor cell clearance, and 2 to 5 -fold less metastases formation in wild-type mice in comparison with the controls [49].

Given the functional and structural features (adhesion, cytotoxicity, zonal differentiation) of the hepatic microvasculature, and the fact that the liver and lung are the most common metastatic target organs, the ability of their vasculatures to produce cytotoxic molecules is of considerable interest as a means to protect the host from circulating metastatic cells. The presence of a tumor-killing defensive mechanism in the liver and lungs provides an additional explanation for tumor cell loss in these secondary organs and helps to explain the inefficient process of cancer metastasis.

\section{Cancer metastatic cascade modified}

The compelling data elaborated above on regulations of liver cancer metastasis by the hepatic microvascular adhesive and cytotoxic functions prompted us to review the classic metastatic cascade again, which includes the primary tumor cell local invasion, intravasation, circulation, adhesion and extravasation, survival and proliferation in the secondary organ $[3,4,8,22,77]$. A new step in which tumor cells pass through the host endothelial defensive mechanisms has been incorporated into the traditional model (Figure 2).

\section{Conclusion}

In summary, there is convincing evidence that hepatic endothelial adhesive and cytotoxic properties can significantly influence the interactions between metastatic tumor cells and the liver with a consequence of altering the formation of liver metastases. In addition, the hepatic endothelial adhesive and cytotoxic functions are inducible, zonal, heterogeneous, affected by sinusoidal structural alterations, and can interact with each other synergistically or counteractively. Together they provide the liver with a specific vascular bed with extensive diversity and flexibility to fight against invading metastatic tumor cells and other tissue injuries. A similar inducible antitumor defensive mechanism also exists in the pulmonary microvascular bed. The molecular mechanisms of the hepatic endothelial cytotoxicity are beginning to be identified. Production of NO and other ROSs from the sinusoidal endothelium causes damage to tumor cell DNA, cell membrane, and protein macromolecules. This natural defensive mechanism in the hepatic and pulmonary microvasculature contributes to our understanding of tumor cell loss in the secondary organ, helps to explain cancer metastatic inefficiency, and is an additional barrier to metastasis in the classic model of the cancer metastatic cascade.

\section{Competing interests}

The author(s) declare that they have no competing interests.

\section{Authors' contributions}

HHW performed the work on hepatic adhesion molecule expression, NO cytotoxicity to tumor cells, regulation of cancer metastasis by LPS stimulation, and wrote the review manuscript. HQ performed the work on NO cytotoxicity in the lungs, iNOS induction by arresting tumor cells in the liver, NO detection by DAF-2 DA and participated in the manuscript revision. QK performed the work on visualizing NO production in the liver by DAF-2 DA, melanoma metastasis in cirrhotic livers and participated in the manuscript revision. FWO was the supervisor of all studies, publications and performed the revision of the review. All authors have read and approved the final manuscript.

\section{Acknowledgements}

We thank all of our colleagues and coauthors in our publications for their significant contributions to our published work and excellent collaboration in our studies. Our work was supported by the Medical Research Council of Canada, Canadian Institutes of Health Research, National Institutes of 
Health (USA), National Cancer Institute (USA) and Susan G. Komen Breast Cancer Foundation (USA).

\section{References}

I. Poste G, Fidler II: The pathogenesis of cancer metastasis. Nature 1980, 283:139-|46.

2. Glaves D, Huben RP, Weiss L: Haematogenous dissemination of cells from human renal adenocarcinomas. $\mathrm{Br} J$ Cancer 1988 57:32-35.

3. Gassmann P, Enns A, Haier J: Role of tumor cell adhesion and migration in organ-specific metastasis formation. Onkologie 2004, 27:577-582.

4. Umansky V, Schirrmacher V, Rocha M: New insights into tumorhost interactions in lymphoma metastasis. I Mol Med 1996, 74:353-363.

5. Weiss L: Metastatic inefficiency: intravascular and intraperitoneal implantation of cancer cells. Cancer Treat Res 1996 , 82: I-II.

6. Sugarbaker $\mathrm{PH}$ : Metastatic inefficiency: the scientific basis for resection of liver metastases from colorectal cancer. J Surg Oncol Suppl 1993, 3:158-160.

7. Chambers AF, Naumov GN, Varghese HJ, Nadkarni KV, MacDonald IC, Groom AC: Critical steps in hematogenous metastasis: an overview. Surg Oncol Clin N Am 200I, I0:243-55.

8. Chambers AF, Groom AC, MacDonald IC: Dissemination and growth of cancer cells in metastatic sites. Nat Rev Cancer 2002 2:563-572.

9. Haier J, Korb T, Hotz B, Spiegel HU, Senninger N: An intravita model to monitor steps of metastatic tumor cell adhesion within the hepatic microcirculation. J Gastrointest Surg 2003, 7:507-5I4

10. Xie K, Huang S: Contribution of nitric oxide-mediated apoptosis to cancer metastasis inefficiency. Free Radic Biol Med 2003 34:969-986.

II. Weiss L: Biomechanical interactions of cancer cells with the microvasculature during hematogenous metastasis. Cance Metastasis Rev 1992, I I:227-235.

12. Weiss L: Biomechanical destruction of cancer cells in skeleta muscle: a rate-regulator for hematogenous metastasis. Clin Exp Metastasis 1989, 7:483-491.

13. Weiss L, Mayhew E, Rapp DG, Holmes JC: Metastatic inefficiency in mice bearing $B \mid 6$ melanomas. $B r J$ Cancer 1982, 45:44-53.

14. Wong CW, Lee A, Shientag L, Yu J, Dong Y, Kao G, Al Mehdi AB, Bernhard El, Muschel RJ: Apoptosis: an early event in metastatic inefficiency. Cancer Res 200I, 6 I:333-338.

15. Wang HH, Mclntosh AR, Hasinoff BB, Rector ES, Ahmed N, Nance DM, Orr FW: Cancer Res 2000, 60:5862-5869.

16. Umansky V, Rocha M, Schirrmacher V: Liver endothelial cells: participation in host response to lymphoma metastasis. Cancer Metastasis Rev 1996, 15:273-279.

17. Paget S: The distribution of secondary growths in cancer of the breast. Lancet 1889, I:99-101.

18. Paget S: The distribution of secondary growths in cancer of the breast. 1889. Cancer Metastasis Rev 1989, 8:98-101.

19. Orr FW, Wang $\mathrm{HH}$ : Tumor cell interactions with the microvasculature: a rate-limiting step in metastasis. Surg Oncol Clin N Am 200I, 10:357-381.

20. Orr FW, Wang HH, Lafrenie RM, Scherbarth S, Nance DM: Interactions between cancer cells and the endothelium in metastasis. J Pathology 2000, 190:310-329.

21. Brodt P, Fallavollita L, Bresalier RS, Meterissian S, Norton CR Wolitzky BA: Liver endothelial E-selectin mediates carcinoma cell adhesion and promotes liver metastasis. Int / Cancer 1997, 7I:6I2-619.

22. Jiang WG: Cell adhesion molecules in the formation of liver metastasis. I Hepatobiliary Pancreat Surg 1998, 5:375-382.

23. von Sengbusch A, Gassmann P, Fisch KM, Enns A, Nicolson GL, Haier $\mathrm{J}$ : Focal adhesion kinase regulates metastatic adhesion of carcinoma cells within liver sinusoids. Am J Pathol 2005 , 1 66:585-596.

24. Scherbarth S, Orr FW: Intravital videomicroscopic evidence for regulation of metastasis by the hepatic microvasculature: effects of interleukin-Ialpha on metastasis and the location of B I 6F I melanoma cell arrest. Cancer Res 1997, 57:4 I05-4 I I0.
25. Mendoza L, Valcarcel M, Carrascal T, Egilegor E, Salado C, Sim BK, Vidal-Vanaclocha F: Inhibition of cytokine-induced microvascular arrest of tumor cells by recombinant endostatin prevents experimental hepatic melanoma metastasis. Cancer Res 2004, 64:304-310

26. Carrascal MT, Mendoza L, Valcarcel M, Salado C, Egilegor E, Telleria $\mathrm{N}$, Vidal-Vanaclocha F, Dinarello CA: Interleukin- 8 binding protein reduces b 16 melanoma hepatic metastasis by neutralizing adhesiveness and growth factors of sinusoidal endothelium. Cancer Res 2003, 63:491-497.

27. Zubia A, Mendoza L, Vivanco S, Aldaba E, Carrascal T, Lecea B, Arrieta A, Zimmerman T, Vidal-Vanaclocha F, Cossio FP: Application of Stereocontrolled Stepwise [3+2] Cycloadditions to the Preparation of Inhibitors of alpha(4)beta(I)-Integrin-Mediated Hepatic Melanoma Metastasis. Angew Chem Int Ed Engl 2005, 44:2903-2907.

28. Wang HH, Nance DM, Orr FW: Murine hepatic microvascular adhesion molecule expression is inducible and has a zonal distribution. Clin Exp Metastasis 1999, I 7:|49-155.

29. Lopez S, Borras D, Juan-Salles C, Prats N, Domingo M, Marco AJ: Immunohistochemical detection of adhesion molecules intercellular adhesion molecule- I and E-selectin in formalinfixed, paraffin-embedded mouse tissues. Lab Invest 1997, 77:543-544.

30. Wang HH, Mclntosh AR, Hasinoff BB, MacNeil B, Rector E, Nance DM, Orr FW: Regulation of B I6F I melanoma cell metastasis by inducible functions of the hepatic microvasculature. Eur J Cancer 2002, 38: | 26I-I270.

31. Neumann B, Machleidt T, Lifka A, Pfeffer K, Vestweber D, Mak TW Holzmann B, Kronke $M$ : Crucial role of 55 -kilodalton TNF receptor in TNF-induced adhesion molecule expression and leukocyte organ infiltration. J Immunol 1996, I 56:1587-I593.

32. Mendoza L, Olaso E, Anasagasti MJ, Fuentes AM, Vidal-Vanaclocha F: Mannose receptor-mediated endothelial cell activation contributes to B I6 melanoma cell adhesion and metastasis in liver. J Cell Physiol 1998, I 74:322-330.

33. Khatib AM, Kontogiannea M, Fallavollita L, Jamison B, Meterissian S Brodt P: Rapid induction of cytokine and E-selectin expression in the liver in response to metastatic tumor cells. Cancer Res |999, 59: |356-|36|.

34. Langley RR, Carlisle R, Ma L, Specian RD, Gerritsen ME, Granger DN: Endothelial expression of vascular cell adhesion molecule-I correlates with metastatic pattern in spontaneous melanoma. Microcirculation 200I, 8:335-345.

35. Mendoza L, Carrascal T, De Luca M, Fuentes AM, Salado C, Blanco I Vidal-Vanaclocha F: Hydrogen peroxide mediates vascular cell adhesion molecule-I expression from interleukin-18-activated hepatic sinusoidal endothelium: implications for circulating cancer cell arrest in the murine liver. Hepatology 2001 , 34:298-310.

36. Jungermann K: Zonal liver cell heterogeneity. Enzyme 1992 46:5-7.

37. Bouwens L, De Bleser P, Vanderkerken K, Geerts B, Wisse E: Liver cell heterogeneity: functions of non-parenchymal cells. Enzyme 1992, 46: I55-168.

38. Jungermann K. Functional heterogeneity of periportal and perivenous hepatocytes. Enzyme 1986, 35:161-180.

39. Reid LM, Fiorino AS, Sigal SH, Brill S, Holst PA: Extracellular matrix gradients in the space of Disse: relevance to liver biology. Hepatology 1992, I 5: I | 98-1203.

40. Asumendi A, Alvarez A, Martinez I, Smedsrod B, Vidal-Vanaclocha F: Hepatic sinusoidal endothelium heterogeneity with respect to mannose receptor activity is interleukin-I dependent. Hepatology 1996, 23:1521-1529.

4I. Barbera-Guillem E, Rocha M, Alvarez A, Vidal-Vanaclocha F: Differences in the lectin-binding patterns of the periportal and perivenous endothelial domains in the liver sinusoids. Hepatology 1991, | 4:131-139.

42. Steinhoff G, Behrend M, Schrader B, Pichlmayr R: Intercellular immune adhesion molecules in human liver transplants: overview on expression patterns of leukocyte receptor and ligand molecules. Hepatology 1993, I 8:440-453.

43. Steinhoff G, Behrend M, Schrader B, Duijvestijn AM, Wonigeit K: Expression patterns of leukocyte adhesion ligand molecules on human liver endothelia. Lack of ELAM-I and CD62 inducibility on sinusoidal endothelia and distinct distribution of 
VCAM-I, ICAM-I, ICAM-2, and LFA-3. Am J Pathol 1993 I 42:48I-488.

44. Qi K, Qiu H, Sun D, Minuk GY, Lizardo M, Rutherford J, Orr FW: Impact of cirrhosis on the development of experimental hepatic metastases by BI6FI melanoma cells in C57BL/6 mice. Hepatology 2004, 40: I I44- I I 50.

45. Xie K, Huang S: Regulation of cancer metastasis by stress pathways. Clin Exp Metastasis 2003, 20:3 I-43.

46. Umansky V, Ushmorov A, Ratter F, Chlichlia K, Bucur M, Lichtenauer A, Rocha M: Nitric oxide-mediated apoptosis in human breast cancer cells requires changes in mitochondrial functions and is independent of CD95 (APO-I/Fas). Int J Oncol 2000, 16:109-117.

47. Jessup JM, Battle $\mathrm{P}$, Waller H, Edmiston $\mathrm{KH}$, Stolz DB, Watkins SC, Locker J, Skena K: Reactive nitrogen and oxygen radicals formed during hepatic ischemia- reperfusion kill weakly metastatic colorectal cancer cells. Cancer Res 1999, 59:1825-1829.

48. Doi K, Akaike T, Horie H, Noguchi Y, Fujii S, Beppu T, Ogawa M, Maeda $\mathrm{H}$ : Excessive production of nitric oxide in rat solid tumor and its implication in rapid tumor growth. Cancer 1996 77(Suppl): I598-1604.

49. Oiu $H$, Orr FW, Jensen $D$, Wang $H H$, Mclntosh AR, Hasinoff $B B$ Nance DM, Pylypas S, Qi K, Song C, Muschel RJ, Al Mehdi AB: Arrest of B 16 Melanoma Cells in the Mouse Pulmonary Microcirculation Induces Endothelial Nitric Oxide Synthase-Dependent Nitric Oxide Release that Is Cytotoxic to the Tumor Cells. Am J Pathol 2003, I 62:403-4I2.

50. Ziegler T, Silacci P, Harrison VJ, Hayoz D: Nitric oxide synthase expression in endothelial cells exposed to mechanical forces. Hypertension 1998, 32:35I-355.

5I. Ballermann BJ, Dardik A, Eng E, Liu A: Shear stress and the endothelium. Kidney Int Suppl 1998, 67:S100-S108.

52. Qi K, Qiu H, Rutherford I, Zhao Y, Nance DM, Orr FW: Direct visualization of nitric oxide release by liver cells after the arrest of metastatic tumor cells in the hepatic microvasculature. J Surg Res 2004, I 1 9:29-35.

53. Rocha M, Kruger A, Van Rooijen N, Schirrmacher V, Umansky V: Liver endothelial cells participate in T-cell-dependent host resistance to lymphoma metastasis by production of nitric oxide in vivo. Int $J$ Cancer 1995, 63:405-4II.

54. Edmiston KH, Shoji Y, Mizoi T, Ford R, Nachman A, Jessup JM: Role of nitric oxide and superoxide anion in elimination of low metastatic human colorectal carcinomas by unstimulated hepatic sinusoidal endothelial cells. Cancer Res 1998 , 58:|524-|53|.

55. Jessup JM, Laguinge L, Lin S, Samara R, Aufman K, Battle P, Frantz M, Edmiston $\mathrm{KH}$, Thomas $\mathrm{P}$ : Carcinoembryonic antigen induction of IL- 10 and IL-6 inhibits hepatic ischemic/reperfusion injury to colorectal carcinoma cells. Int I Cancer 2004, I I I:332-337.

56. Moon BK, Lee YJ, Battle P, Jessup JM, Raz A, Kim HR: Galectin-3 protects human breast carcinoma cells against nitric oxideinduced apoptosis: implication of galectin-3 function during metastasis. Am J Pathol 200I, I 59: 1055-1060.

57. Anasagasti MJ, Alvarez A, Martin JJ, Mendoza L, Vidal-Vanaclocha F: Sinusoidal endothelium release of hydrogen peroxide enhances very late antigen-4-mediated melanoma cell adherence and tumor cytotoxicity during interleukin-I promotion of hepatic melanoma metastasis in mice. Hepatology 1997, 25:840-846.

58. Anasagasti MJ, Alvarez A, Avivi C, Vidal-Vanaclocha F: InterleukinI-mediated $\mathrm{H} 2 \mathrm{O} 2$ production by hepatic sinusoidal endothelium in response to B 16 melanoma cell adhesion. J Cell Physiol 1996, 167:314-323.

59. Li LM, Nicolson GL, Fidler IJ: Direct in vitro lysis of metastatic tumor cells by cytokine-activated murine vascular endothelial cells. Cancer Res 1991, 5 I:245-254.

60. Li LM, Kilbourn RG, Adams J, Fidler IJ: Role of nitric oxide in lysis of tumor cells by cytokine-activated endothelial cells. Cance Res 1991, 51:2531-2535.

61. Kim JW, Wong CW, Goldsmith JD, Song C, Fu W, Allion MB, Herlyn $M$, Al Mehdi $A B$, Muschel RJ: Rapid apoptosis in the pulmonary vasculature distinguishes non-metastatic from metastatic melanoma cells. Cancer Lett 2004, 2 1 3:203-2/2.

62. Al Mehdi AB, Zhao G, Dodia C, Tozawa K, Costa K, Muzykantov V, Ross C, Blecha F, Dinauer M, Fisher AB: Endothelial NADPH oxi- dase as the source of oxidants in lungs exposed to ischemia or high K+. Circ Res 1998, 83:730-737.

63. Oldreive C, Rice-Evans C: The mechanisms for nitration and nitrotyrosine formation in vitro and in vivo: impact of diet. Free Radic Res 200I, 35:215-23I.

64. Ischiropoulos $\mathrm{H}$, Beckman JS: Oxidative stress and nitration in neurodegeneration: cause, effect, or association? I Clin Invest 2003, III:163-169

65. Wink DA, Mitchell JB: Chemical biology of nitric oxide: Insights into regulatory, cytotoxic, and cytoprotective mechanisms of nitric oxide. Free Radic Biol Med 1998, 25:434-456.

66. Kong L, Dunn GD, Keefer LK, Korthuis RJ: Nitric oxide reduces tumor cell adhesion to isolated rat postcapillary venules. Clin Exp Metastasis 1996, 14:335-343.

67. Hickey MJ: Role of inducible nitric oxide synthase in the regulation of leucocyte recruitment. Clin Sci (Lond) 200I, 100:I-12.

68. Hickey MJ, Granger DN, Kubes P: Inducible nitric oxide synthase (iNOS) and regulation of leucocyte/endothelial cell interactions: studies in iNOS-deficient mice. Acta Physiol Scand 200I, 173:119-126.

69. Serracino-Inglott F, Habib NA, Mathie RT: Hepatic ischemiareperfusion injury. Am J Surg 200I, I8I:160-166.

70. Liu P, Xu B, Hock CE, Nagele R, Sun FF, Wong PY: NO modulates P-selectin and ICAM-I mRNA expression and hemodynamic alterations in hepatic I/R. Am J Physiol 1998, 275:H2 I9I-H2I98.

71. Menger MD, Richter S, Yamauchi J, Vollmar B: Role of microcirculation in hepatic ischemia/reperfusion injury. Hepatogastroenterology 1999, 46(Suppl 2): | 452-| 457.

72. Anasagasti MJ, Olaso E, Calvo F, Mendoza L, Martin JJ, Bidaurrazaga J, Vidal-Vanaclocha F: Interleukin I-dependent and -independent mouse melanoma metastases. I Natl Cancer Inst 1997. 89:645-65I.

73. Vidal-Vanaclocha F, Amezaga C, Asumendi A, Kaplanski G, Dinarello $\mathrm{CA}$ : Interleukin-I receptor blockade reduces the number and size of murine B 16 melanoma hepatic metastases. Cancer Res 1994, 54:2667-2672.

74. Vidal-Vanaclocha F, Alvarez A, Asumendi A, Urcelay B, Tonino P, Dinarello CA: Interleukin I (IL-I)-dependent melanoma hepatic metastasis in vivo; increased endothelial adherence by IL-I. induced mannose receptors and growth factor production in vitro. J Natl Cancer Inst 1996, 88: 1 98-205.

75. Barbera-Guillem E, Alonso-Varona A, Vidal-Vanaclocha F: Selective implantation and growth in rats and mice of experimental liver metastasis in acinar zone one. Cancer Res 1989 49:4003-40I0.

76. Varghese HJ, Mackenzie LT, Groom AC, Ellis CG, Ryan A, MacDonald IC, Chambers AF: In vivo videomicroscopy reveals differential effects of the vascular-targeting agent ZD6 I 26 and the antiangiogenic agent ZD6474 on vascular function in a liver metastasis model. Angiogenesis 2004, 7:157-164.

77. Weiss L, Ward PM: Cell detachment and metastasis. Cancer Metastasis Rev 1983, 2:111-127.
Publish with Bio Med Central and every scientist can read your work free of charge

"BioMed Central will be the most significant development for disseminating the results of biomedical research in our lifetime. "

Sir Paul Nurse, Cancer Research UK

Your research papers will be:

- available free of charge to the entire biomedical community

- peer reviewed and published immediately upon acceptance

- cited in PubMed and archived on PubMed Central

- yours - you keep the copyright

Submit your manuscript here:

http://www.biomedcentral.com/info/publishing_adv.asp
BioMedcentral 